\title{
The Burden of Jetlag among Nigerians Studying in Indian and Malaysian Universities
}

\author{
Ahmed Dahiru Balami ${ }^{1 *}$ MBBS, MPH, FRSPH, Ibrahim Abdu Wakawa², MBBS, MHPM, MSc, FWACP
}

${ }^{1}$ Department of Community Health, Universiti Putra Malaysia

*Corresponding author

Ahmed Dahiru Balami, Department of Community Health, Universiti

Putra Malaysia, E-mail: ahdahiru@yahoo.com

${ }^{2}$ Department of Mental Health, University of Maiduguri, Nigeria

Submitted: 08 Oct 2017; Accepted: 15 Oct 2017; Published: 20 Oct 2017

\begin{abstract}
Background: There are a large number of Nigerians studying and aspiring to study in India and Malaysia. Due to the great time-zone differences between Nigeria and these countries, there exists the possibility of experiencing adjustment problems.
\end{abstract}

Aim of the study: To determine the burden of jetlag phenomenon and the distribution of its symptoms among Nigerians studying in these countries.

Methodology: Online surveys using Google forms were disseminated to Nigerians studying in Indian and Malaysian Universities and the data were analyzed.

Results: A hundred and three (103) eligible persons responded to the survey, most of whom were males (86.4\%) and married (58.3\%). Many of them did not know what jetlag was (52.4\%). Most, also reported falling asleep less easily on their first night of arrival (78.6\%), of whom 44.4\% continued to experience same for months and even up to a year. Many also reported having more wakeful episodes during the night (41.7\%); later waking time (56.3\%); feeling less alert 30 minutes after waking from sleep (58.3\%) and generally feeling more tired since arrival (57.3\%), with many of them haven experienced same for prolonged durations. A higher proportion of those studying in Malaysia, reported experiencing these symptoms, compared to those studying in India. As an adjustment/coping technique, most of them had attempted maintaining daytime alertness (72.8\%) and maintaining a dark room at night (55.3\%), of whom $21.0 \%$ and $31.6 \%$ respectively found these measures very effective, while $57.3 \%$ and $50.8 \%$ respectively found them slightly effective.

Conclusions: This study reveals the great enormity of this problem. It is recommended that prospective students be enlightened on the possibility of experiencing this problem and adjustment techniques even before departure from Nigeria. School clinics in these countries should also include jetlag management in their treatment programs to help affected international students.

Keywords: Jet lag, Universities, India, Malaysia, Nigeria

\section{Introduction}

The American Academy of Sleep Medicine (AASM) defines jet lag as insomnia or sleepiness, with impaired total sleep time, after crossing a minimum of two time zones, with impairment of daytime function, general malaise or somatic symptoms within one or two days of travel, in the absence of other causes of these symptoms [1]. It occurs after journeys in which three or more time-zones have been crossed [2]. They are the result of a shift in the usual circardian rhythm, in an effort to adjust to the new environment [3]. This adjustment of the biological clock to phase shifts in the external environment does not occur immediately [4]. The occurrence of these symptoms have been reported to be more severe in east-ward travels [5]. Previous studies on jet lag phenomenon seem to have been conducted among short stay visitors like athletes and conference attendees [6-8]. Despite the high number of Nigerians as current and prospective students in India and Malaysia; the huge east-ward time-zone differences between Nigeria and these two countries; and the possibility of adjustment problems arising as a result, there has been no previous attempt to study this phenomenon among this population. The aim of this study was to determine the burden of jetlag phenomenon and adaptation strategies among Nigerians studying in these countries.

\section{Materials and Methods}

Malaysia and India are located east-wards away from Nigeria, with their local times, seven hours and four and a half hours respectively ahead of the local time in Nigeria. This research utilised a crosssectional study design in which online surveys using Google forms were used to disseminate a structured questionnaire to Nigerians studying in Indian and Malaysian Universities after permission to carry out this research had been obtained from the Office of 
Presidents of the Nigerian students Community of Malaysia and India. The questionnaire was adopted from the Liverpool jetlag questionnaire [9]. Data was retrieved and analysed using Statistical Package for Social Sciences (SPSS) version 22. Frequencies and percentages, were used to summarise the data. Chi-squared test was used to determine whether or not, differences existed between the two countries in the symptoms they experienced. In the chisquared test analysis, samples with missing data were excluded.

\section{Results}

The respondents' socio-demographic characteristics are presented in Table 1. A total of one hundred and three (103) eligible persons responded to the survey. Their ages from 20 to 47 years with median + IQR $(31+10)$. Most were males $(86.4 \%)$ and from the North-western part of Nigeria $(54.4 \%)$. Only $27.2 \%$ were undergraduates, with rest being Masters and Doctor of Philosophy (Ph.D.) students. Over a half were studying in Malaysia (55.3\%).

Table 1: Socio-demographic characteristics of respondents

\begin{tabular}{|l|c|}
\hline Variables & \\
\hline Age & \\
\hline Median + IQR & $31+10$ \\
\hline Range & $20-47$ \\
\hline Gender & Freq. (\%) \\
\hline Male & $89(86.4$ \\
\hline Female & $13(12.6)$ \\
\hline Missing & $1(1.0)$ \\
\hline Total & $103(100)$ \\
\hline Region of origin & Freq. (\%) \\
\hline North-east & $56(2.9)$ \\
\hline North-west & $28(54.4)$ \\
\hline North-central & $7(27.2)$ \\
\hline South-east & $1(6.8)$ \\
\hline South-west & $8(1.0)$ \\
\hline Missing & $3(2.9)$ \\
\hline Total & $103(100)$ \\
\hline Marital status & Freq. (\%) \\
\hline Single & $43(41.7)$ \\
\hline Married & $60(58.3)$ \\
\hline Total & $103(100)$ \\
\hline Course of study & Freq. (\%) \\
\hline Bachelor & $28(27.2)$ \\
\hline Masters & $37(35.9)$ \\
\hline PhD & $36(35.0)$ \\
\hline Missing & $2(1.9)$ \\
\hline Total & Freq. (\%) \\
\hline Country of study & $(42.7)$ \\
\hline India & \\
\hline Malaysia & \\
\hline Missing & (100) \\
\hline Total & \\
\hline
\end{tabular}

Less than half of the respondents were aware of the phenomenon called jetlag $(46.6 \%)$ as shown in Figure 1. Table 2 presents the sleep-related problems experienced by some of the respondents. Most of them (78.6\%) fell asleep less easily on the first night of their arrival, out of whom $44.44 \%$ continued to experience same for months and even up to a year. Many of them had also experienced other symptoms of jetlag phenomenon on their first night of arrival like: having more wakeful episodes during the night (41.7\%); later waking time $(56.3 \%)$ and feeling less alert 30 minutes after waking from sleep $(58.3 \%)$.

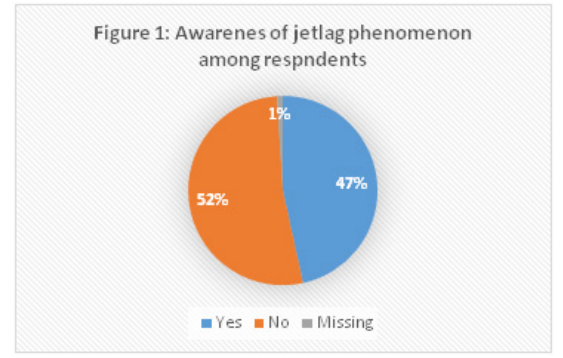

Table 2: Sleep-related experiences by respondents since arrival

\begin{tabular}{|c|c|c|}
\hline Variable & Frequency (n) & Percentage (\%) \\
\hline \multicolumn{3}{|c|}{ Ease of sleeping at first night of arrival } \\
\hline Less easily & 81 & 78.6 \\
\hline Same easily & 19 & 18.4 \\
\hline More easily & 3 & 2.9 \\
\hline Total & 103 & 100 \\
\hline \multicolumn{3}{|c|}{ Time of first night's sleep } \\
\hline Earlier & 19 & 18.4 \\
\hline Same & 16 & 15.5 \\
\hline Later & 68 & 66.0 \\
\hline Total & 103 & 100 \\
\hline \multicolumn{3}{|c|}{ Well sleep on first night } \\
\hline Fewer waking & 35 & 34.0 \\
\hline Same & 25 & 24.3 \\
\hline More waking & 43 & 41.7 \\
\hline Total & 103 & 100 \\
\hline \multicolumn{3}{|l|}{ Waking time } \\
\hline Earlier & 26 & 25.2 \\
\hline Same & 17 & 16.5 \\
\hline Later & 58 & 56.3 \\
\hline Total & 103 & 100 \\
\hline \multicolumn{3}{|c|}{ Alertness 30 mins after waking } \\
\hline Less & 60 & 58.3 \\
\hline Same & 23 & 22.3 \\
\hline More & 17 & 16.5 \\
\hline Missing & 3 & 2.9 \\
\hline Total & 103 & 100 \\
\hline
\end{tabular}

Other autonomic experiences by the respondents are presented in Table 3. Many reported feeling generally more tired since arrival $(57.3 \%)$.However, fewer persons reported having other symptoms 
like: a worse level of concentration since arrival (34\%); lower level of motivation (32.0\%); greater irritability (22.3\%); more bowel movements (13.6\%) and a loser stool consistency (21.4). A great number of the respondents even reported having a better level of concentration (43.7\%), with higher levels of motivation $(51.5 \%)$ since arrival at their countries of study.

Table 3: Other autonomic experiences by respondents since arrival

\begin{tabular}{|c|c|c|}
\hline Variable & Frequency (n) & Percentage (\%) \\
\hline \multicolumn{3}{|c|}{ Tired since arrival } \\
\hline Less & 20 & 19.4 \\
\hline Same & 21 & 20.4 \\
\hline More & 59 & 57.3 \\
\hline Missing & 3 & 2.9 \\
\hline Total & 103 & 100 \\
\hline \multicolumn{3}{|c|}{ Concentration on arrival } \\
\hline Worse & 35 & 34 \\
\hline Same & 21 & 20.4 \\
\hline Better & 45 & 43.7 \\
\hline Missing & 2 & 1.9 \\
\hline Total & 103 & 100 \\
\hline \multicolumn{3}{|c|}{ Motivation since arrival } \\
\hline Less & 33 & 32.0 \\
\hline Same & 13 & 12.6 \\
\hline More & 53 & 51.5 \\
\hline Missing & 4 & 3.9 \\
\hline Total & 103 & 100 \\
\hline \multicolumn{3}{|c|}{ Irritability since arrival } \\
\hline Less & 49 & 47.6 \\
\hline Same & 22 & 21.4 \\
\hline More & 23 & 22.3 \\
\hline Missing & 9 & 8.7 \\
\hline Total & 103 & 100 \\
\hline \multicolumn{3}{|c|}{ Bowel movement } \\
\hline Less & 34 & 33.0 \\
\hline Same & 49 & 47.6 \\
\hline More & 14 & 13.6 \\
\hline Missing & 6 & 5.8 \\
\hline Total & 103 & 100 \\
\hline \multicolumn{3}{|c|}{ Stool consistency } \\
\hline Looser & 22 & 21.4 \\
\hline Same & 47 & 45.6 \\
\hline Harder & 26 & 25.2 \\
\hline Missing & 8 & 7.8 \\
\hline Total & 103 & 100 \\
\hline
\end{tabular}

As seen in Table 4, for those who experienced those adverse jetlag symptoms, onlyaround a quarter of them had those experiences for only a few days. For the remaining majority, those symptoms had lasted for weeks and even up to a year.
Table 4: Duration for which symptoms lasted

\begin{tabular}{|c|c|c|}
\hline Slept less easily since first night & Frequency (n) & Percentage (\%) \\
\hline Days & 29 & 35.8 \\
\hline Weeks & 16 & 19.8 \\
\hline Months & 20 & 24.7 \\
\hline Up to a year & 16 & 19.8 \\
\hline Total & 81 & 100 \\
\hline Slept later since first night & Frequency $(\mathbf{n})$ & Percentage (\%) \\
\hline Missing & 3 & 4.4 \\
\hline Days & 13 & 19.1 \\
\hline Weeks & 19 & 27.9 \\
\hline Months & 20 & 29.4 \\
\hline Up to a year & 13 & 19.1 \\
\hline Total & 68 & 100 \\
\hline Had later waking times & Frequency (n) & Percentage (\%) \\
\hline Missing & 3 & 5.2 \\
\hline Days & 11 & 19.0 \\
\hline Weeks & 15 & 25.9 \\
\hline Months & 17 & 29.3 \\
\hline Up to a year & 12 & 20.7 \\
\hline Total & 58 & 100 \\
\hline Felt less alert since arrival & Frequency (n) & Percentage (\%) \\
\hline Missing & 6 & 10.0 \\
\hline Days & 17 & 28.3 \\
\hline Weeks & 14 & 23.3 \\
\hline Months & 15 & 25.0 \\
\hline Up to a year & 8 & 13.3 \\
\hline Total & 60 & 100 \\
\hline Feeling tired since arrival & Frequency (n) & Percentage (\%) \\
\hline Missing & 5 & 8.5 \\
\hline Days & 13 & 22.0 \\
\hline Weeks & 18 & 30.5 \\
\hline Months & 14 & 23.7 \\
\hline Up to a year & 9 & 15.3 \\
\hline Total & 59 & 100 \\
\hline
\end{tabular}

Table 5 presents a comparison of symptoms by country of study. There was no significant difference between those studying in Malaysia and India in their knowledge of jetlag; ease of falling asleep; number of waking episodes and level of alertness 30 minutes after waking. However, those studying in Malaysia reported sleeping later $(\chi 2=16.68 ; \mathrm{df}=6 ; \mathrm{p}=0.011)$; waking up later $(\chi 2=25.78 ; \mathrm{df}=4 ; \mathrm{p}<0.001)$ and feeling more tiredness $(\chi 2=21.74$; $\mathrm{df}=6 ; \mathrm{p}=0.001)$ compared to those studying in India. 
Table 5: Comparison of jetlag symptoms by country of study

\begin{tabular}{|c|c|c|c|c|c|}
\hline \multirow[t]{2}{*}{ Jetlag symptom } & \multicolumn{5}{|c|}{ Country of study } \\
\hline & $\begin{array}{l}\text { India } \\
\text { Freq. (\%) } \\
\mathrm{n}=\mathbf{4 5}\end{array}$ & $\begin{array}{l}\text { Malaysia } \\
\text { Freq. (\%) } \\
\mathbf{n}=\mathbf{5 6}\end{array}$ & $\chi^{2}$ & $d f$ & $p$ \\
\hline $\begin{array}{l}\text { Ease of sleeping at } \\
\text { first night of arrival }\end{array}$ & & & - & - & $0.066 \mathrm{a}$ \\
\hline Less easily & $30(66.7)$ & $49(87.5)$ & & & \\
\hline Same easily & $12(26.7)$ & $7(12.5)$ & & & \\
\hline More easily & $3(6.7)$ & $0(0.0)$ & & & \\
\hline Total & $45(100)$ & $56(100)$ & & & \\
\hline $\begin{array}{l}\text { Time of first } \\
\text { night's sleep }\end{array}$ & & & 23.05 & 2 & $<0.001 *$ \\
\hline Earlier & $17(37.8)$ & $2(3.6)$ & & & \\
\hline Same & $9(20.0)$ & $7(12.5)$ & & & \\
\hline Later & $19(42.2)$ & $47(83.9)$ & & & \\
\hline Total & $45(100)$ & $56(100)$ & & & \\
\hline Waking time & & & 7.87 & 2 & $0.02 *$ \\
\hline Earlier & $14(31.1)$ & $20(35.7)$ & & & \\
\hline Same & $17(37.8)$ & $8(14.3)$ & & & \\
\hline Later & $14(31.1)$ & $28(50.0)$ & & & \\
\hline Total & $45(100)$ & $56(100)$ & & & \\
\hline $\begin{array}{l}\text { Alertness } 30 \\
\text { minutes after waking }\end{array}$ & & & 17.13 & 2 & $<0.001$ \\
\hline Less & $19(43.2)$ & $7(12.7)$ & & & \\
\hline Same & $10(22.7)$ & $7(12.7)$ & & & \\
\hline More & $15(34.1)$ & $41(74.5)$ & & & \\
\hline Total & $44(100)$ & $55(100)$ & & & \\
\hline Tired since arrival & & & 3.16 & 2 & 0.206 \\
\hline Less & $9(20.9)$ & $11(19.6)$ & & & \\
\hline Same & $12(26.9)$ & $8(14.3)$ & & & \\
\hline More & $22(51.2)$ & $37(66.1)$ & & & \\
\hline Total & $43(100)$ & $56(100)$ & & & \\
\hline
\end{tabular}

Note: $(*)$ - significant $\mathrm{p}<0.05$; (a) - Fisher's exact test

As presented in Table 6, most of them had attempted maintaining daytime alertness $(72.8 \%)$ as a measure to tackle the problem of jetlag, and $21 \%$ of those who did, reported it to be very effective, while $57.33 \%$ had reported it to be slightly effective. Many had also attempted maintaining a dark room at night (55.3\%), of whom $31.58 \%$ had reported it to be very effective, while $50.88 \%$ said it was slightly effective. Chi-squared test results also revealed that for each of the symptoms studied, there was no significant difference by gender or marital status.
Table 6: Coping measures adopted by some respondents

Frequency of Those who Adopted Some Coping Strategies

\begin{tabular}{|l|l|l|}
\hline Type of strategy & Frequency (n) & Percentage (\%) \\
\hline
\end{tabular}

\section{Day time alertness}

\begin{tabular}{|l|c|c|}
\hline Yes & 75 & 72.8 \\
\hline No & 23 & 22.3 \\
\hline Missing & 5 & 4.9 \\
\hline Total & 103 & 100
\end{tabular}

Maintaining a dark room

\begin{tabular}{|l|c|c|}
\hline Yes & 57 & 55.3 \\
\hline No & 42 & 40.8 \\
\hline Missing & 4 & 3.9 \\
\hline Total & 103 & 100 \\
\hline
\end{tabular}

Effectiveness of Coping Strategies among Those Who Adopted Them

\begin{tabular}{|l|c|c|}
\hline Type of strategy & Frequency (n) & Percentage (\%) \\
\hline Day time alertness & \multicolumn{2}{|l|}{} \\
\hline Missing & 4 & 5.3 \\
\hline Not effective & 7 & 9.3 \\
\hline Slightly effective & 43 & 57.3 \\
\hline Very effective & 21 & 28.0 \\
\hline Total & 75 & 100 \\
\hline Maintaining a dark room & \multicolumn{2}{|}{} \\
\hline Missing & 2 & 3.5 \\
\hline Not effective & 8 & 14.0 \\
\hline Slightly effective & 29 & 50.9 \\
\hline Very effective & 18 & 31.6 \\
\hline Total & 57 & 100 \\
\hline
\end{tabular}

\section{Discussion}

All the respondents were adults, as none was below the age of 18 years. The distribution of course of study among respondents also shows that Nigerians were more likely to go for post-graduate studies in those countries as less than a third $(27.2 \%)$ were undergraduate students. Over three fourths $(78.6 \%)$ had reported difficulties in falling asleep on their first nights of arrival to their respective countries of study. This agrees with an earlier report that only onethird of travellers do not experience jet lag symptoms [10]. Despite its enormity and the high academic levels of the respondents, over a half of them did not know what jet lag was. The east-ward location of the two countries relative to Nigeria, meant that their usual sleeping time in Nigeria before departure were reached earlier, in their new time-zones, posing adjustment problems to their biological clocks [11], explaining the difficulty in initiating sleep on the first night of their arrival. Their later waking times could be explained by their late sleeping time, while the lower level of alertness after waking could likely have been from the sleepiness after waking, due to insufficient sleep the last night.

The greater level of tiredness among the respondents could be explained by the several hours journey they had covered from Nigeria to India or Malaysia. Better study facilities and motivating study environments are the likely reasons why the respondents experienced better concentration and motivation in their new 
countries of study. As many as $13.3 \%$ to $20.7 \%$ had experienced those symptoms for up to a year demonstrating how persistent they could be, among certain individuals. This is a serious problem requiring intervention, as chronic jet lag has been reported to cause temporal lobe atrophy and spatial cognitive deficits [12]. For all jet lag symptoms reported, the proportion of those who experienced each one of them was higher among those in Malaysia compared to those in India though not all were statistically significant, which agrees with earlier findings of higher severity with more time zones crossed [13].

The two coping strategies of maintaining a dark room and maintaining day time alertness had to a large extent proven effective. It is as such, recommended that prospective students be enlightened on the possibility of experiencing this problem and on adjustment techniques even before departure from Nigeria. School clinics in these countries should also incorporate into their services rendered, jetlag management, to help affected international students. Melatonin treatment has also been reported to be very effective [14]. Further studies are also required to better understand the molecular basis of jet lag so as to discover more effective treatment options.

\section{Conclusion}

Most Nigerians studying in Malaysia and India have reported experiencing jet lag symptoms. The prolonged duration of these symptoms are also worrisome. Despite the enormity of the problem however, the majority are unaware of it. There is as such the need for raising awareness among prospective and current students on this phenomenon, and putting in place treatment programmes for affected persons. Similar studies should also be replicated among others, studying in countries with time-zones at least three hour's different from theirs.

\section{References}

1. American Academy of Sleep Medicine (AASM). (2014) International Classification of Sleep Disorders: Diagnostic and Coding Manual.3rd ed. Darien, IL: American Academy of Sleep Medicine.

2. Waterhouse J, Reilly T, Atkinson G, Edwards B (2007) Jet lag: trends and coping strategies. Lancet 369: 1117-1129.

3. Sack RL (2010) Clinical Practice. Jet Lag. New England Journal of Medicine 362: 440-447.

4. Comperatore CA, Krueger GP (1990) Circadian rhythm desynchronosis, jet lag, shift lag, and coping strategies. Occup Med 5: 323-341.

5. Monk T, Buysse D, Carrier J, Kupfer D (2000) Inducing jetlag in older people: Directional asymmetry. J Sleep Res 9: 101-116.

6. Spitzer RL, Terman M, Williams JBW, Terman JS, Malt, UF, et al. (1999) Jet Lag: Clinical Features, Validation of a New Syndrome-Specific Scale, and Lack of Response to Melatonin in a Randomized, Double-Blind Trial. Am J Psychiatry 156: 1392-1396.

7. Waterhouse J, Edwards B, Nevill A, Carvalho S, Atkinson G, et al. (2002) Identifying some determinants of "jet lag" and its symptoms: a study of athletes and other travellers British Journal of Sports Medicine 36: 54-60.

8. BeckerT, PenzelT, FietzeI (2014) A new German Charité Jet Lag Scale for jet lag symptoms and application. Ergonomics 58: 811-821.

9. Waterhouse J, Edwards B, Nevill A, Atkinson G, Reilly T, et al. (2000) Do subjective symptoms predict our perception of jet lag? Ergonomics 43: 1514-1527.

10. Kryger M, Roth T, Dement, W (2005) Principles and Practice of Sleep Medicine. 4th ed. Philadelphia, PA: Elsevier/ Saunders.

11. Sack RL (2010) “Clinical Practice. Jet Lag." New England Journal of Medicine 362: 440-447.

12. Kwangwook C, Ennaceur A, Cole JC, Suh CK (2000) Chronic Jet Lag Produces Cognitive Deficits. Journal of Neuroscience 20: RC66 (1-5).

13. Monk T (2005) Aging human circadian rhythms: conventional wisdom may not always be right. J Biol Rhythms 20: 366-374.

14. Herxheimer A, Petrie KJ (2002) Melatonin for the prevention and treatment of jet lag. Cochrane Database of Systematic Reviews 2: CD001520.
Copyright: (02017 Ahmed Dahiru Balami. This is an open-access article distributed under the terms of the Creative Commons Attribution License, which permits unrestricted use, distribution, and reproduction in any medium, provided the original author and source are credited. 